Received Date : 03-Mar-2015

Revised Date : 08-Sep-2015

Accepted Date : 14-Sep-2015

Article type : Original Article

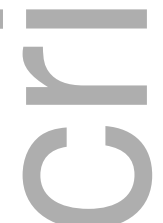

$153-2015 . R 2$

Original Article

\title{
A case series of anal melanoma including the results of treatment with Imatinib in selected patients
}

\section{Authors}

J. Knowles , A C. Lynch ${ }^{2}$, S K Warrier ${ }^{2}$, M. Henderson ${ }^{2}$, A G Heriot ${ }^{2}$

${ }^{1}$ Department of Colorectal Surgery, Royal Free Hospital, London, United Kingdom

${ }^{2}$ Department of Cancer Surgery, Peter MacCallum Cancer Centre, Melbourne, Australia

Correspondence: jonathan.knowles@NHS.NET

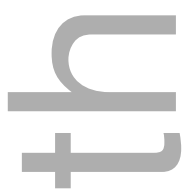

\section{Abstract}

Aim: Anal melanoma is a rare malignancy with a poor prognosis.

Methods: All patients with a diagnosis of anal melanoma treated at a single institution between 2000 and 2012 were identified and their treatment and outcome were evaluated.

This is the author manuscript accepted for publication and has undergone full peer review but has not been through the copyediting, typesetting, pagination and proofreading process, which may lead to differences between this version and the Version of Record. Please cite this article as doi: 10.1111/CODI.13209

This article is protected by copyright. All rights reserved 
Results: Sixteen patients had a median survival of 2.9 years. Fourteen had stage I or II disease with a median survival of 4.0 years and progression-free survival of 1.5 years. When used for disease staging, whole body PET/CT identified an additional three sites of metastasis in 5 patients compared with computed tomography $(\mathrm{CT})$ of the chest, abdomen and pelvis. Surgery involved wide local excision (WLE) or abdominoperineal resection (APR) with respective local recurrence rates of $50 \%$ and $66 \%$. Eleven patients underwent testing for c-Kit mutations, of whom five were positive. Four of these were treated with the tyrosine kinase inhibitor, Imatinib, and showed rapid response of metastases outside the central nervous system (CNS).

Discussion: The outcome of this malignancy remains poor. PET is the modality of choice for disease staging. Testing tumours for c-Kit mutations may allow selected patients to participate in trials of tyrosine kinase inhibitors.

\section{What does this paper add to the literature?}

The article adds to the small volume of literature relating to the prognosis and treatment of anal melanoma. In particular it reports some success of Imatinib in reducing the disease burden in patients with metastatic anal melanoma outside the central nervous system.

\section{Introduction}

Anal melanoma is rare, comprising only $1-2 \%$ of all melanomas and $4 \%$ of anal tumours $(1,2)$. Two thirds appear as pigmented lesions in the anal canal or anal margin. They are often friable and ulcerating, presenting with rectal bleeding. A third lack pigment and may present as an incidental finding during proctological procedures such as haemorrhoidectomy (3). Lesions are commonly discovered late and metastasise early with a consequent poor outcome. The main determinant of prognosis is the stage at presentation. This is divided into stage 1 ; confined to primary site, stage 2 ; regional lymph node spread which can be to pelvic or inguinal nodes and stage 3; distant metastatic spread. Median survival for patients with stage 1, stage 2 and stage 3 disease is reported to be 34,13 and 10 months (4). Patients who develop local recurrence after treatment or systemic metastasis have a mean survival of only 10 months $(5,6)$. The mainstay of local treatment is surgical resection with either abdominoperineal resection (APR) or wide local excision (WLE). Patients with metastatic disease may be offered chemotherapy as used for cutaneous melanoma, unfortunately response rates are low and the duration of response short. 
Genotyping has identified molecular pathways which are targets for new treatments. In cutaneous melanoma the MAP kinase pathway and mutations in B-RAF have been identified leading to the use of specific inhibitors of B-RAF and MEK (7). Such treatment has demonstrated high rates of response but of limited duration. The tyrosine kinase c-Kit undergoes an activating mutation or is amplified in some mucosal melanomas. This can usually be demonstrated by strongly positive immunohistochemical staining $(8,9)$. A number of tyrosine kinase inhibitors (TKI) have been developed, some such as Imatinib are specific inhibitors of c-Kit and have been used in a small number of patients with mucosal melanoma (10).

This case series examines our experience in the management of anal melanoma over the last decade, including the use of whole body FDG-PET/CT (PET) scanning for staging, the outcome of surgery for local disease control and the identification of tumours with abnormalities of c-Kit and treatment with tyrosine kinase inhibitors (TKI).

\section{Method}

Patients presenting with anal melanoma to the Peter MacCallum Cancer Center, Melbourne Australia between 1/1/2000 until 1/3/2012 were included. Cases were identified by searching the pathology and oncology databases using the keywords 'anal and melanoma' and 'mucosal and melanoma'. Patients were included if they were treated at the institute for primary disease or disease recurrence. Institutional ethics board approval was granted. The diagnosis was confirmed by review of histology and immunohistochemistry where appropriate.

Data collection included demographics, tumour pathology, imaging, management and outcome data. Overall survival, progression free survival, with $95 \%$ confidence intervals (CI) and one, two and five year survival and progression free survival were calculated using the Kaplan-Meier method. All analyses were done in R version 2.15.0 using the survival function in the package "survival" (11).

The management of these tumours was not standardised as they presented uncommonly over a long period. Our unit now routinely stages patients with PET/CT, but this form of imaging was not available during the early years as it started in 2000. A group of patients had both PET/CT and CT performed preoperatively either because an additional PET was performed on referral to our centre which we then compared to the CT scan taken in the referring hospital or because both were performed in our centre. Patients with stage 1 and 2 disease 
underwent surgical resection while patients with stage 3 disease were treated with palliative systemic therapy and were not considered for palliative surgical resection. When surgery was undertaken at our centre WLE was performed if macroscopic clearance was considered achievable. If regional lymph node involvement was suspected preoperatively an APR or groin dissection was used to include these sites. Disease recurrence or progression was determined by clinical assessment and cross sectional imaging. Patients were tested for c-Kit and $\mathrm{B}-\mathrm{RAF}$ mutations once the presence of systemic disease was proven and if the tests were available. TKIs were given to patients with proven distant metastases and a mutation in cKit. One patient was treated with Sorafenib and the remainder received the more selective antagonist Imatinib. For patients undergoing systemic therapy a metabolic response to treatment was inferred from changes in FDG avidity on PET.

\section{Results}

Sixteen patients with anal melanoma were identified, ten $(63 \%)$ of whom were female. The median age was 66 (27-83) years. At presentation ten patients had stage 1, four stage 2 and two stage 3 disease. Both patients with stage 3 disease had regional node involvement as well as systemic metastases. The most common presentations were an anal lump or rectal bleeding (six patients each). Three cases were an unexpected finding during haemorrhoidectomy. A further case was identified following APR for what was thought to be an adenocarcinoma: this lesion was in the anorectum. The remaining lesions were in the anal canal (9 patients) or at the anal verge (6 patients). Regional spread was to inguinal nodes in three patients and pelvic nodes in three.

Overall survival was 2.9 [CI 1.22-undefined] years (Figure 1.). The two patients with stage 3 disease survived 0.3 and 0.7 years. The median overall survival of the 14 patients with stage 1 or 2 disease $(n=14)$ was 4.0 [95\% CI 1.8 - undefined] years. One, two and five year survival rates were $86 \%$ [CI 69.2-100], 57\% [CI 34-95] and 38\% [CI 18-82]. Median progression free survival was 1.5 [95\% confidence interval 0.9 - undefined] years (Figure 2). One, two and five year progression free survival rates in these 14 patients disease were $64 \%$ [CI 44-95], 40\% [21-78] and $24 \%$ [5-57]. 
All patients who underwent preoperative PET scanning demonstrated FDG avidity at the primary site. Five patients had a preoperative PET and a CT scan of the chest, abdomen and pelvis. The former demonstrated an additional three sites of metastasis compared with CT alone (two nodal, one systemic). Five patients had PET as their only staging modality and metastatic lymph nodes were identified in four.

The results of surgery are given in Table 1 . Two patients treated with WLE and radiotherapy remained disease free for 17 and 18 years. Both were referred to our centre with recurrent disease although given the long interval from the original diagnosis, the development of a metachronous new primary melanoma was possible. Six patients underwent WLE, five required a further WLE to achieve clear margins within a month of initial surgery. Local recurrence occurred in three of these patients. Six patients underwent APR which achieved negative margins in all cases but despite this local recurrence occurred in four. Clinically these recurrences presented as multifocal and extensive nodules in the cutaneous and pelvic tissue. This pattern is very different to that seen in squamous cell and adenocarcinoma of the anus and rectum where recurrence occurs adjacent to the original tumour site or in residual nodal tissue.

Of the eleven specimens which were tested for c-Kit mutation five (45\%) were positive. Eight were tested for B-Raf and all were negative. The outcome of patients with a c-Kit mutation compared to those without is shown in Table 2. One patient was treated with Sorafenib after initial Dacarbazine treatment and all the subsequent patients were treated with the more specific c-Kit inhibitor Imatinib. One of these was switched from Imatinib to Dasantanib better to treat brain metastasis as Imatinib has poor central nervous system (CNS) penetration. One patient had Dacarbazine initially and was then switched to Imatinib. Two patients suffered a skin reaction to Imatinib but both continued with treatment. A full course of Dacarbazine wass completed in only six of the patients. The poor completion rates in this group were due to rapid progression of metastatic disease and the need for palliative care.

\section{Discussion}

Other studies of anal melanoma show similar demographic and stage specific survival data $(2,4,12-14)$. They also show a similarly rapid disease progression, in line with the finding in the present study of only 1.5 years from diagnosis to the development systemic metastases. Once a patient has developed systemic disease life expectancy is less than one year $(5,6)$. If metastases can be identified earlier then earlier systemic treatment can be started. Anal 
melanomas being highly metabolically active are good lesions for FDG tracer uptake. We demonstrated the clinical usefulness of PET/CT for disease staging, but did not have sufficient data to do a similar comparison on its value for detecting disease progression during surveillance, although PET is now used routinely in our unit for this purpose. Studies of cutaneous melanoma have shown that FDG-PET is superior to CT alone in identifying regional nodal disease and solid organ metastasis with a specificity of $83 \%$ and sensitivity of $85 \%(15,16)$ and the present study has demonstrated that this is also the case for anal malignant melanoma

The primary tumour can be surgically treated using either WLE or APR. If it is possible to undertake WLE with clear margins, this is the treatment of choice. A number of studies have shown that there is no survival advantage of patients who undergo APR compared with WLE. WLE is therefore favoured because it has considerably less morbidity and avoids a permanent stoma $(4,5,6,14,17)$. The present series demonstrates the difficulty of achieving local control with either surgical approach. Patients who underwent WLE commonly required multiple resections to achieve microscopically negative margins. While all the patients who underwent APR had negative resection margins this did not equate to a reduction in local recurrence with rates of $66 \%$ for APR and 50\% for WLE. Other series have found high rates of local recurrence for both operations, including 20-30\% for APR and 26-58\% for WLE $(3,14,17)$. In our study patients underwent APR either because they had a large primary tumour or because they had pelvic nodal disease. The local recurrences they developed were multifocal suggesting numerous foci of occult melanoma cells were left in cutaneous tissue or small lymphatics outside the field of radical surgery. We know lymph node involvement and probably large primary size are indicators of greater aggressiveness with a poorer prognosis (17). It is likely that this at least partly explains the high rates of local recurrence seen in the APR patients. The use of adjuvant radiotherapy has been recommended by a study from MD Anderson Hospital (18) and it is reasonable to think it would help to treat microscopic disease outside the field of surgical excision. WLE was used to remove macroscopic disease and APR when WLE would not achieve this. Both sets of patients were then treated with a short course of adjuvant radiotherapy in high doses including treatment to the inguinal and pelvic nodal areas resulting in five year local control rates of $74 \%$ and $84 \%$ (18). In view of the poor rates of local control at our centre adjuvant radiotherapy should be studied further.

We did not find any B-RAF mutations in our specimens which is in agreement with other studies, although why B-RAF is not involved in the pathogenesis is not understood (7). We 
did find a high rate of c-Kit mutations and the prevalence of $45 \%$ was higher than in previous studies which had rates nearer 15\% (19). Identifying c-Kit mutations allowed us to initiate treatment with tyrosine kinase inhibitors. Sorafenib is a less specific antagonist of c-Kit than Imatinib but has been shown to have some effect in a previous case report of anal melanoma (20). C-Kit inhibition in patients with mucosal melanoma has also been reported to have some useful effect (8) and the four patients in the present study who were treated with Imatinib all improved symptomatically. They also all showed a metabolic response on PET in both systemic and lymph node metastasis whereas there was no response in patients receiving standard palliative chemotherapy with Dacarbazine. Despite these encouraging findings there was, however, no increase in survival. One of the difficulties in management is that once progression is identified it is very rapid and occurs in multiple sites. In view of the poor survival of patients with stage 2 disease, those with c-Kit mutations could be considered for adjuvant treatment with TKIs and this is an area that may warrant further study. Three of the four patients treated with Imatinib developed or had progression of existing brain metastases. The CNS penetration of Imatinib is poor and the brain is a sanctuary site for these metastases, but the fourth who did not have CNS involvement remained alive with no PET avid disease almost two years after developing systemic metastasis. This offers some hope for selected patients with anal melanoma in a disease which has seen little improvement in outcome over many years (2).

It is strongly recommended that patients with anal malignant melanoma are referred to specialist centres with expertise in treating both colorectal cancer and melanoma. The outcome of treatment should be carefully audited and where useful published. We also recommend testing tumours for c-Kit at diagnosis. Patients with c-Kit positive stage 3 disease or those whose disease progresses should be entered into trials of Imatinib treatment and those with stage 2 disease may be considered for trials of adjuvant treatment (neither indication is approved by the FDA). Imaging of the brain should be undertaken with CT or MRI and patients with brain metastases should be considered for treatment with Dasantanib as it has better CNS penetration. Hopefully new therapies will continue to be found in cutaneous and mucosal melanoma which can then be trialled in selected cases of anal melanoma as these rare tumours remain very difficult to treat.

\section{References}


(1) Longo WE, Vernava AM, III, Wade TP, Coplin MA, Virgo KS, Johnson FE. Rare anal canal cancers in the U.S. veteran: patterns of disease and results of treatment. Am Surg 1995 Jun;61(6):495-500.

(2) Ragnarsson-Olding BK, Nilsson PJ, Olding LB, Nilsson BR. Primary ano-rectal malignant melanomas within a population-based national patient series in Sweden during 40 years. Acta Oncol 2009;48(1):125-31.

(3) Chang AE, Karnell LH, Menck HR. The National Cancer Data Base report on cutaneous and noncutaneous melanoma: a summary of 84,836 cases from the past decade. The American College of Surgeons Commission on Cancer and the American Cancer Society. Cancer 1998 Oct 15;83(8):1664-78.

(4) Podnos YD, Tsai NC, Smith D, Ellenhorn JD. Factors affecting survival in patients with anal (16)

(5) Roumen RM. Anorectal melanoma in The Netherlands: a report of 63 patients. Eur J Surg Oncol 1996 Dec;22(6):598-601.

(6) Brady MS, Kavolius JP, Quan SH. Anorectal melanoma. A 64-year experience at Memorial Sloan-Kettering Cancer Center. Dis Colon Rectum 1995 Feb;38(2):146-51. melanoma. Am Surg 2006 Oct;72(10):917-20.

(7) Davies H, Bignell GR, Cox C, Stephens P, Edkins S, Clegg S, et al. Mutations of the BRAF gene in human cancer. Nature 2002 Jun 27;417(6892):949-54.

(8) Antonescu CR, Busam KJ, Francone TD, Wong GC, Guo T, Agaram NP, et al. L576P KIT mutation in anal melanomas correlates with KIT protein expression and is sensitive to specific kinase inhibition. Int J Cancer 2007 Jul 15;121(2):257-64.

(9) Satzger I, Schaefer T, Kuettler U, Broecker V, Voelker B, Ostertag H, et al. Analysis of cKIT expression and KIT gene mutation in human mucosal melanomas. Br J Cancer 2008 Dec 16;99(12):2065-9. 
(10) Satzger I, Kuttler U, Volker B, Schenck F, Kapp A, Gutzmer R. Anal mucosal melanoma with KIT-activating mutation and response to imatinib therapy--case report and review of the literature. Dermatology 2010;220(1):77-81.

(11) R: A Language and Environment for Statistical Computing, R Core Team, R Foundation for Statistical Computing, Vienna, Austria, 2013,

(12) Nilsson PJ, Ragnarsson-Olding BK. Importance of clear resection margins in anorectal malignant melanoma. Br J Surg 2010 Jan;97(1):98-103.

(13) Belli F, Gallino GF, Lo VS, Mariani L, Poiasina E, Leo E. Melanoma of the anorectal region: the experience of the National Cancer Institute of Milano. Eur J Surg Oncol 2009 Jul;35(7):757-62.

(14) Droesch JT, Flum DR, Mann GN. Wide local excision or abdominoperineal resection as the initial treatment for anorectal melanoma? Am J Surg 2005 Apr;189(4):446-9.

(15) Bastiaannet E, Wobbes T, Hoekstra OS, van der Jagt EJ, Brouwers AH, Koelemij R, et al. Prospective comparison of [18F]fluorodeoxyglucose positron emission tomography and computed tomography in patients with melanoma with palpable lymph node metastases: diagnostic accuracy and impact on treatment. J Clin Oncol 2009 Oct 1;27(28):4774-80.

(16) Krug B, Crott R, Lonneux M, Baurain JF, Pirson AS, Vander BT. Role of PET in the initial staging of cutaneous malignant melanoma: systematic review. Radiology 2008 Dec;249(3):836-44.

(17) Kiran RP, Rottoli M, Pokala N, Fazio VW. Long-term outcomes after local excision and radical surgery for anal melanoma: data from a population database. Dis Colon Rectum 2010 Apr;53(4):402-8.

(18) Ballo MT, Gershenwald JE, Zagars GK, Lee JE, Mansfield PF, Strom EA, et al. Sphincter-sparing local excision and adjuvant radiation for anal-rectal melanoma. J Clin Oncol 2002 Dec 1;20(23):4555-8. 
(19) Torres-Cabala CA, Wang WL, Trent J, Yang D, Chen S, Galbincea J, et al. Correlation between KIT expression and KIT mutation in melanoma: a study of 173 cases with emphasis on the acral-lentiginous/mucosal type. Mod Pathol 2009 Nov;22(11):1446-56.

(20) Quintas-Cardama A, Lazar AJ, Woodman SE, Kim K, Ross M, Hwu P. Complete response of stage IV anal mucosal melanoma expressing KIT Val560Asp to the multikinase inhibitor sorafenib. Nat Clin Pract Oncol 2008 Dec;5(12):737-40.

Table 1. Comparison of the results of different treatments including further surgery to achieve clear margins, local recurrence, disease free survival and progression to distant metastases. *margin status unknown in one patient.

APR abdominoperineal excision

WLE wide local excision

\begin{tabular}{|c|c|c|c|c|c|}
\hline \begin{tabular}{|l|l|} 
Initial & Pati \\
Surgery & ents \\
\end{tabular} & $\begin{array}{l}\text { Margins } \\
\text { involved }\end{array}$ & $\begin{array}{l}\text { Further } \\
\text { surgery }\end{array}$ & $\begin{array}{l}\text { Local } \\
\text { recurrence }\end{array}$ & $\begin{array}{l}\text { Disease } \\
\text { Free } \\
\text { Survival/ } \\
\text { days }\end{array}$ & $\begin{array}{l}\text { Disease } \\
\text { progression/days }\end{array}$ \\
\hline APR & 0 & None & 4 & 216 & 314 \\
\hline \begin{tabular}{l|l|} 
Wide & 6 \\
Local & \\
Excision & \\
\end{tabular} & $5^{*}$ & $\begin{array}{l}5 \text { local excision } \\
3 \text { salvage APR }\end{array}$ & 3 & 479 & 570 \\
\hline \begin{tabular}{l|l|} 
WLE + & 2 \\
Adjuvant & \\
Radiothe & \\
rapy &
\end{tabular} & 1 & $\begin{array}{l}2 \text { local excision } \\
1 \text { salvage APR }\end{array}$ & 2 & 18 years & None \\
\hline
\end{tabular}


Table 2. The outcome of 11 patients tested for c-Kit mutation. Response to treatment was based on clinical findings and imaging with PET.

* denotes patient is still alive; time taken to latest follow up.

\begin{tabular}{|c|c|c|c|c|c|}
\hline $\begin{array}{l}\text { c-Kit } \\
\text { Mutati } \\
\text { on }\end{array}$ & Treatment & $\begin{array}{l}\text { Survival with } \\
\text { systemic } \\
\text { therapy/ days }\end{array}$ & $\begin{array}{l}\text { Disease } \\
\text { progress } \\
\text { ion from } \\
\text { diagnosi } \\
\text { s/ days }\end{array}$ & $\begin{array}{l}\text { Survi } \\
\text { val } \\
\text { from } \\
\text { diagn } \\
\text { osis/ } \\
\text { days }\end{array}$ & Response to treatment \\
\hline Yes & $\begin{array}{l}\text { Sorafenib } \\
\text { 200mg BD and } \\
\text { Dacarbazine }\end{array}$ & 64 & 100 & 446 & $\begin{array}{l}\text { Some symptomatic improvement. } \\
\text { Progression of brain metastasis. }\end{array}$ \\
\hline Yes & $\begin{array}{l}\text { Imatinib 400mg } \\
\text { daily }\end{array}$ & 49 & 0 & 103 & $\begin{array}{l}\text { Regression of liver and lung } \\
\text { disease, progression of primary, } \\
\text { local nodes and brain metastasis. }\end{array}$ \\
\hline Yes & $\begin{array}{l}\text { Imatinib 600mg } \\
\text { twice daily, } \\
\text { Changed to } \\
\text { Dasantanib after } \\
13 / 12\end{array}$ & 444 & 1211 & 1872 & $\begin{array}{l}\text { Partial metabolic response at } 42 \\
\text { days, complete at } 75 \text {. Changed to } \\
\text { Dasantanib to increase CNS } \\
\text { penetration. Continued } \\
\text { progression of brain metastasis. }\end{array}$ \\
\hline Yes & $\begin{array}{l}\text { Imatinib 400mg } \\
\text { daily }\end{array}$ & $547 *$ & 2099 & $2871 *$ & $\begin{array}{l}\text { Complete metabolic response in } \\
\text { liver lung and groin. }\end{array}$ \\
\hline Yes & $\begin{array}{l}\text { Imatinib 400mg } \\
\text { daily and } \\
\text { Dacarbazine }\end{array}$ & $117 *$ & 321 & $366^{*}$ & $\begin{array}{l}\text { Near complete regression of lung } \\
\text { metastases and mediastinal nodes. } \\
\text { Brain metastases unchanged. }\end{array}$ \\
\hline $\begin{array}{l}\text { No }(6 \\
\text { patient } \\
\text { s) }\end{array}$ & $\begin{array}{l}\text { Dacarbazine (3 } \\
\text { patients } \\
\text { completed } \\
\text { course) }\end{array}$ & 220 & 342 & 712 & $\begin{array}{l}\text { No response seen on post - } \\
\text { treatment imaging. No ongoing } \\
\text { survivors. }\end{array}$ \\
\hline
\end{tabular}


Fig 1 Kaplan-Meier curve of overall survival. 95\% confidence intervals represented by dashed lines $(\mathrm{n}=16)$.

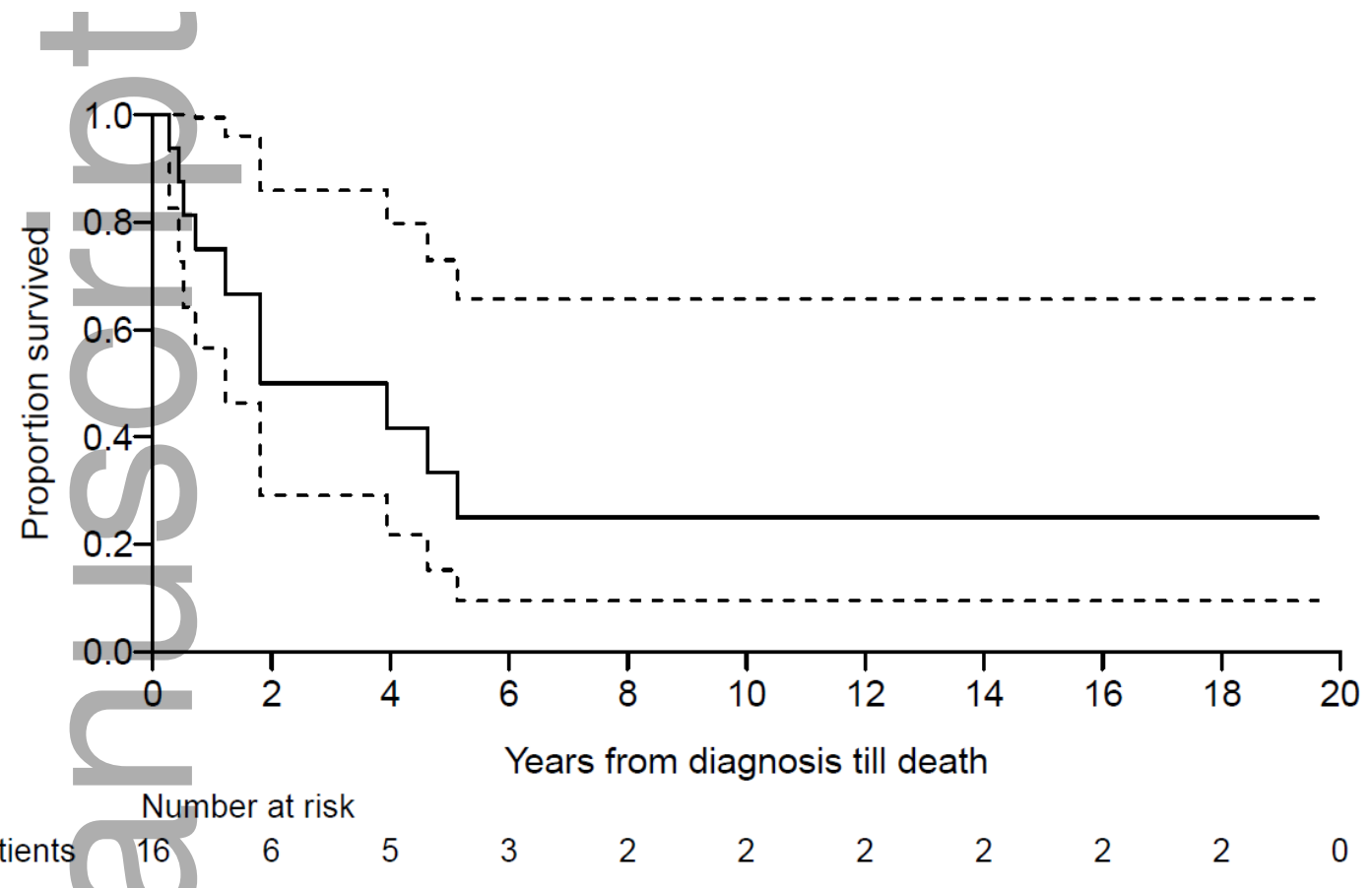

Fig 2 Kaplan-Meier curve of progression free survival. 95\% confidence intervals represented by dashed lines $(n=14)$.

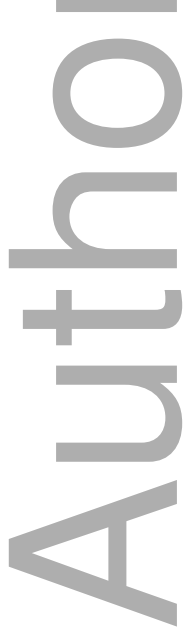



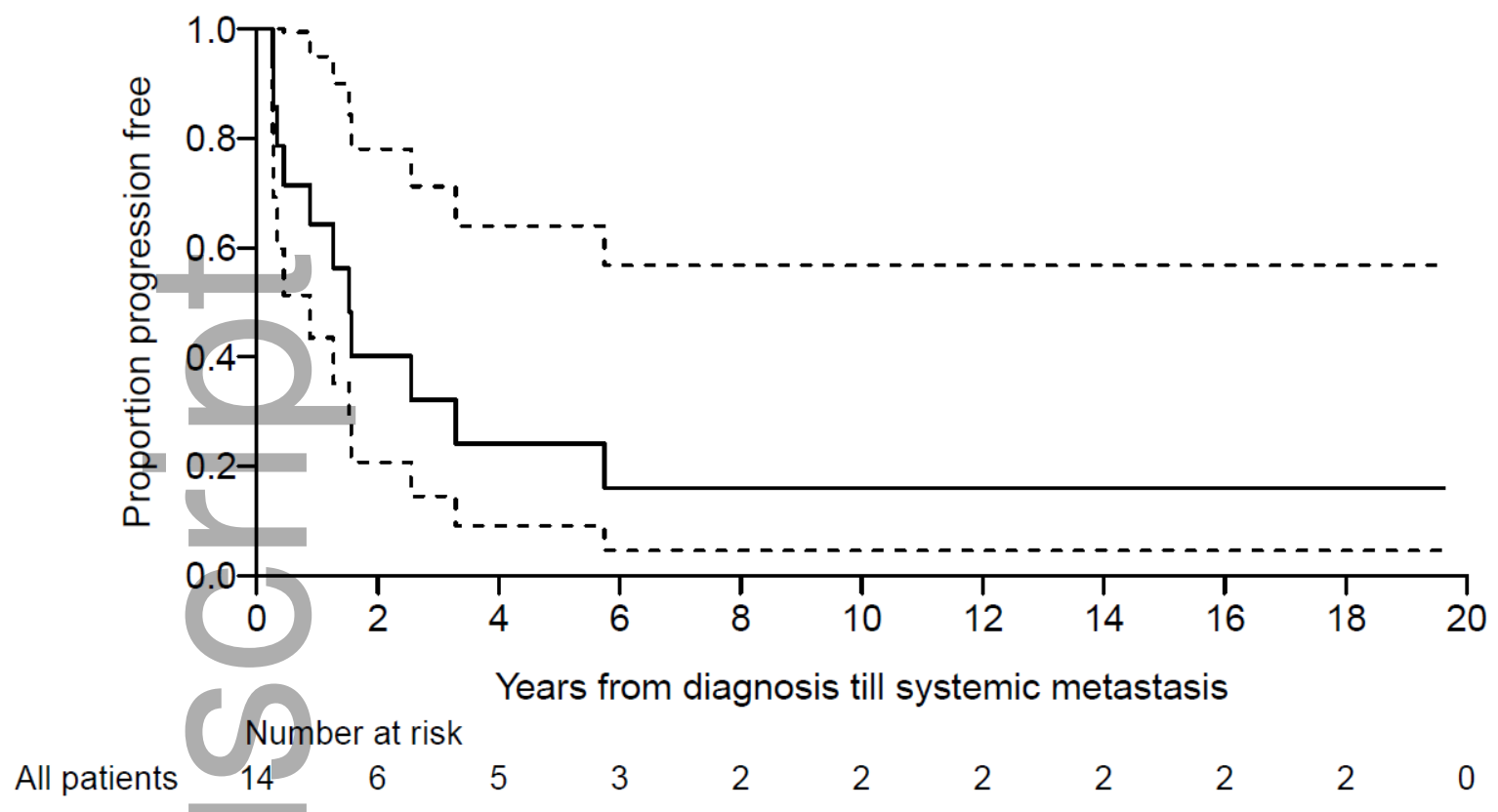


\section{University Library}

\section{- M M N E R VA A gateway to Melbourne's research publications}

Minerva Access is the Institutional Repository of The University of Melbourne

Author/s:

Knowles, J;Lynch, AC;Warrier, SK;Henderson, M;Heriot, AG

Title:

A case series of anal melanoma including the results of treatment with imatinib in selected patients

Date:

2016-09-01

Citation:

Knowles, J., Lynch, A. C., Warrier, S. K., Henderson, M. \& Heriot, A. G. (2016). A case series of anal melanoma including the results of treatment with imatinib in selected patients. COLORECTAL DISEASE, 18 (9), pp.877-882. https://doi.org/10.1111/codi.13209.

Persistent Link:

http://hdl.handle.net/11343/291679 